\title{
Equation of state and thermal stability of $\mathrm{Al}_{3} \mathrm{BC}$
}

\author{
Vladimir L. Solozhenko ${ }^{\mathrm{a}, *}$, Elena G. Solozhenko ${ }^{\mathrm{b}}$, Christian Lathe ${ }^{\mathrm{c}}$ \\ ${ }^{a}$ LPMTM-CNRS, Institut Galilée, Université Paris Nord, 99, av. J.B. Clément, F-93430 Villetaneuse, France \\ ${ }^{\mathrm{b}}$ Institute for Superhard Materials of the National Academy of Sciences of Ukraine, Kiev 04074, Ukraine \\ ${ }^{\mathrm{c}}$ Hamburger Synchrotronstrahlungslabor (HASYLAB-DESY), D-22607 Hamburg, Germany
}

Received 19 September 2005; received in revised form 12 January 2006; accepted 12 January 2006 by B. Jusserand

Available online 31 January 2006

\begin{abstract}
The lattice parameters of $\mathrm{Al}_{3} \mathrm{BC}$ have been measured up to $5 \mathrm{GPa}$ at ambient temperature using energy-dispersive X-ray powder diffraction with synchrotron radiation. A fit to the experimental $p-V$ data using Birch-Murnaghan equation of state gives values of the $\mathrm{Al}_{3} \mathrm{BC}$ bulk modulus

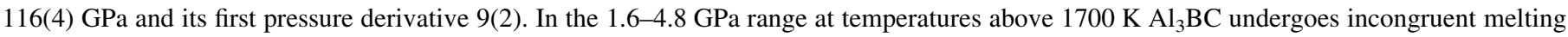
that results in the formation of $\mathrm{Al}_{3} \mathrm{BC}_{3}, \mathrm{AlB}_{2}$ and liquid aluminum.
\end{abstract}

(C) 2006 Elsevier Ltd. All rights reserved.

PACS: 61.10.Eq; 64; 64.30.+t

Keywords: A. Aluminum boroncarbide; C. XRD; E. High pressure

\section{Introduction}

Aluminum-rich phases of the Al-B-C system have been the topic of several recent investigations because cermets based on aluminum boroncarbide are promising ceramic materials of high hardness and low density. In fabrication of advanced $\mathrm{Al} / \mathrm{B} / \mathrm{C}$ cermets, the basic product of a reaction between aluminum and boron carbide at relatively low temperatures is $\mathrm{Al}_{3} \mathrm{BC}$ [1]. This phase was first described as phase $\mathrm{X}$ [2]. Later Meyer and Hillebrecht [3] synthesized the pure compound and defined its composition and crystal structure (Fig. 1). As no data are found in the literature on the $\mathrm{Al}_{3} \mathrm{BC}$ high-pressure behavior, our interest has been in studying the equation of state and thermal stability of this phase up to $5 \mathrm{GPa}$ using X-ray powder diffraction with synchrotron radiation.

\section{Experimental}

Pure $\mathrm{Al}_{3} \mathrm{BC}$ was synthesized at $1150 \mathrm{~K}$ from the elements with an excess of aluminum as described in [3]. Combustion elemental analysis and electron probe microanalysis gave

\footnotetext{
* Corresponding author. Tel.: +3314940 34 89; fax: +33149403938 E-mail address: vls@lpmtm.univ-paris13.fr (V.L. Solozhenko).
}

0038-1098/\$ - see front matter (C) 2006 Elsevier Ltd. All rights reserved. doi:10.1016/j.ssc.2006.01.015 a $\mathrm{Al}: \mathrm{B}: \mathrm{C}$ ratio of about $3: 1: 1$. Secondary ion mass spectroscopy showed that the oxygen impurity content is less than 1 at $\%$.

The high-pressure experiments up to $5 \mathrm{GPa}$ were carried out using a multianvil X-ray system MAX80 at beamline F2.1, HASYLAB-DESY. The experimental set-up has been described elsewhere [4]. Energy-dispersive data were collected on a Canberra solid state Ge-detector with fixed Bragg angle $2 \theta=9.238(5)^{\circ}$ using a white beam collimated down to $100 \times$ $100 \mu \mathrm{m}^{2}$ and the detector optics with $2 \theta$ acceptance angle of $0.005^{\circ}$, which ensures a high resolution of the observed diffraction patterns. The detector was calibrated using the $K_{\alpha}$ and $K_{\beta}$ fluorescence lines of $\mathrm{Cu}, \mathrm{Rb}, \mathrm{Mo}, \mathrm{Ag}, \mathrm{Ba}$, and $\mathrm{Tb}$.

To decrease the deviatoric stress that was generated during 'cold' compression and, thus, attain quasi-hydrostatic pressure conditions during equation-of-state measurements, the samples were preannealed at $900 \mathrm{~K}$ and a given pressure for $10 \mathrm{~min}$. The sample pressure was determined from the lattice constant of $\mathrm{NaCl}$ (pressure marker) using Decker's equation of state [5].

The temperature of the high-pressure cell was controlled by a Eurotherm PID-regulator within $\pm 4 \mathrm{~K}$ in the $400-1900 \mathrm{~K}$ range. The sample temperature was measured by a $\mathrm{Pt} / \mathrm{Pt} 10 \% \mathrm{Rh}$ thermocouple. The correction for the pressure effect on the thermocouple emf was made using the data of Getting and Kennedy [6]. Pressures at different temperatures were evaluated from the lattice parameters of highly ordered graphite-like hexagonal boron nitride using the $p-V-T$ equation of state of hBN [4]. The pressure variations with increasing temperature were found not to exceed $\pm 200 \mathrm{MPa}$ in the 2 -mm 


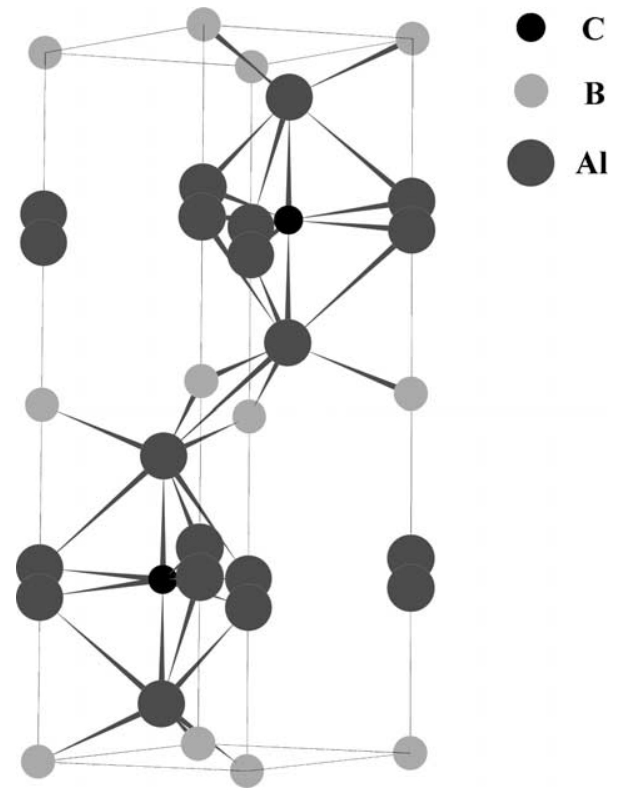

Fig. 1. Crystal structure of $\mathrm{Al}_{3} \mathrm{BC}$ is a closest packing of $\mathrm{Al}$ atoms with a layer sequence $\mathrm{ABACBC}$. Isolated boron atoms are placed in all octahedral voids between the layers $\mathrm{A}$ and $\mathrm{C}$ while isolated carbon atoms occupy half of the trigonal voids in the layers $\mathrm{B}[3]$.

central part of the cell over the experimental temperature range.

In studying $\mathrm{Al}_{3} \mathrm{BC}$ thermal stability, the samples were compressed to a given pressure at ambient temperature, and then the diffraction patterns were collected in the 'autosequence' mode at a linear heating at a rate of $25 \mathrm{~K} / \mathrm{min}$. Collection time was $60 \mathrm{~s}$ for each pattern.

\section{Results and discussion}

\subsection{Equation of state of $A l_{3} B C$}

Synchrotron radiation diffraction patterns of the $\mathrm{Al}_{3} \mathrm{BC}$ subcell exhibit broadened reflections (101), (102), (103), (104),

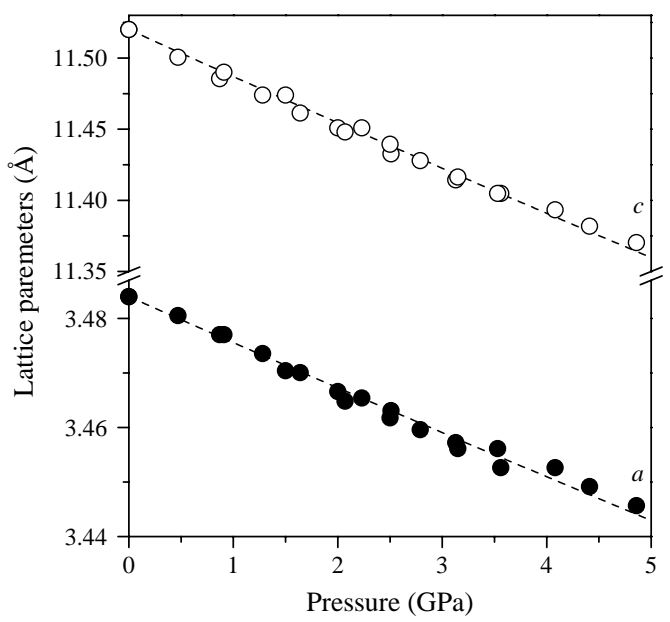

Fig. 2. Lattice parameters of $\mathrm{Al}_{3} \mathrm{BC}$ versus pressure at ambient temperature. The dashed lines represent least-squares fits to the experimental data using Eq. (1).

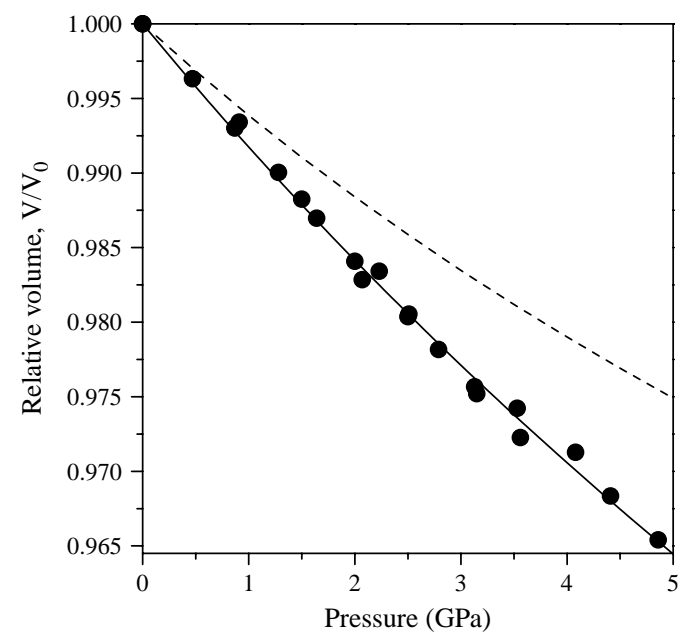

Fig. 3. The $p-V$ data for $\mathrm{Al}_{3} \mathrm{BC}$ at ambient temperature. The solid line is the best fit of the experimental data to the Birch-Murnaghan equation of state, with $B_{0}=116 \mathrm{GPa}$ and $B_{0}^{\prime}=9$. The dashed line is equation of state of $\mathrm{Al}_{3} \mathrm{BC}_{3}$ [7].

(006), (105), (110), (106), and occasionally (004), (108), (202), (204), (116). Lattice parameters of the subcell at ambient pressure were calculated to be $a=3.491 \pm 0.002 \AA$ and $c=11.54 \pm 0.01 \AA$, in good agreement with those reported in [3]. With increasing pressure, the diffraction lines of $\mathrm{Al}_{3} \mathrm{BC}$ broaden and weaken considerably and above $5 \mathrm{GPa}$ only the lines associated with the (102), (103), (104) and (006) reflections could be resolved.

Fig. 2 shows the lattice parameters of $\mathrm{Al}_{3} \mathrm{BC}$ versus pressure. The one-dimensional analog of the first-order Murnaghan equation of state of the form

$\frac{r}{r_{0}}=\left[1+\left(\frac{\beta^{\prime}}{\beta_{0}}\right) p\right]^{-1 / \beta^{\prime}}$

was used for approximation of the non-linear relation between normalized lattice parameters and pressure. Here $r$ is the lattice parameter (index 0 refers to ambient pressure); $\beta_{0}$ is the axial compression modulus ${ }^{1}$, and $\beta^{\prime}$ is the pressure derivative of $\beta_{0}$. The dashed lines in Fig. 2 correspond to Eq. (1) with parameters obtained from a least-squares fit to the experimental data. The ratio between axial compression moduli towards the $a$ and $c$ axes is $1.19 \pm 0.03$, which points to the higher compressibility of $\mathrm{Al}_{3} \mathrm{BC}$ in the $c$-direction. This fact can be attributed to a pronounced two dimensional character of the $\mathrm{Al}_{3} \mathrm{BC}$ crystal structure in which layers of edge sharing $\mathrm{Al}_{6} \mathrm{~B}$ octahedra alternate with layers of trigonal bipyramidal $\mathrm{Al}_{5} \mathrm{C}$ polyhedra linked by common corners [3].

Experimental values of the $\mathrm{Al}_{3} \mathrm{BC}$ relative volume versus pressure are plotted in Fig. 3. A non-linear three-parameter least-squares fit to the experimental $p-V$ data using BirchMurnaghan equation of state gave zero-pressure value of bulk modulus $B_{0}=116 \pm 4 \mathrm{GPa}$ and its pressure derivative $\mathrm{d} B_{0} / \mathrm{d} p=9 \pm 2$. These values point to a higher compressibility of $\mathrm{Al}_{3} \mathrm{BC}$ as compared to $\mathrm{Al}_{3} \mathrm{BC}_{3} \quad\left(B_{0}=153 \mathrm{GPa}\right.$ [7]).

\footnotetext{
${ }^{1}\left(\beta_{0}\right)^{-1}=k_{\mathrm{r}}=-(\mathrm{d} \ln r / \mathrm{d} p)_{p=0}$ is the linear compressibility
} 


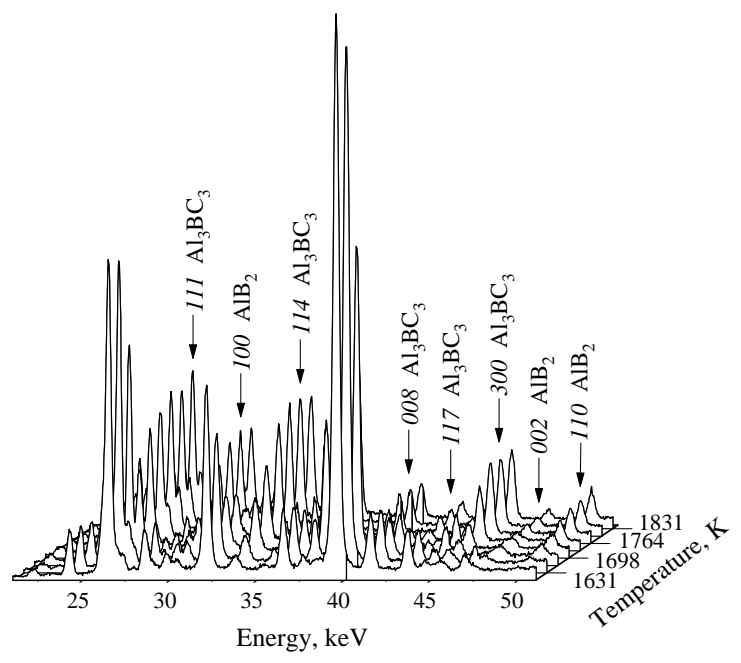

Fig. 4. Diffraction patterns of $\mathrm{Al}_{3} \mathrm{BC}$ taken at a linear-heating rate of $25 \mathrm{~K} / \mathrm{min}$ at $1.6 \mathrm{GPa}$.

The latter is probably due to a clearly ionic character of $\mathrm{Al}_{3} \mathrm{BC}_{3}$ [8] while $\mathrm{Al}_{3} \mathrm{BC}$ seems to be more metallic [3].

\subsection{Phase stability of $\mathrm{Al}_{3} \mathrm{BC}$}

At $1.6 \mathrm{GPa}$ heating of $\mathrm{Al}_{3} \mathrm{BC}$ up to $1680 \mathrm{~K}$ results in a decrease of the lines' width, which is indicative of the structural ordering of the phase at a temperature increase under pressure. Starting with $1680 \mathrm{~K}$, the lines of $\mathrm{Al}_{3} \mathrm{BC}_{3}$ and $\mathrm{AlB}_{2}$ appear in the diffraction patterns (Fig. 4). At the same time a drastic decrease in the intensity of the lines of initial $\mathrm{Al}_{3} \mathrm{BC}$ is observed. A considerable increase of the background points to the formation of a liquid in the system, which gives grounds to conclude that a process of incongruent melting of $\mathrm{Al}_{3} \mathrm{BC}$ takes place:

$3 \mathrm{Al}_{3} \mathrm{BC}=\mathrm{Al}_{3} \mathrm{BC}_{3}+\mathrm{AlB}_{2}+5 \mathrm{Al}$

Complete disappearance of the $\mathrm{Al}_{3} \mathrm{BC}$ lines is observed at about $1700 \mathrm{~K}$. With further temperature increase up to $1850 \mathrm{~K}$, the phase composition of the system does not change because of the high thermal stability of $\mathrm{Al}_{3} \mathrm{BC}_{3}$ [7]. Diffraction patterns of the samples quenched down to ambient conditions exhibits lines of $\mathrm{Al}_{3} \mathrm{BC}_{3}, \mathrm{AlB}_{2}$ and metallic aluminum.

At $4.8 \mathrm{GPa}, \mathrm{Al}_{3} \mathrm{BC}$ decomposition starts at higher temperatures $(1720 \pm 20 \mathrm{~K})$ and also results in the formation of $\mathrm{Al}_{3} \mathrm{BC}_{3}, \mathrm{AlB}_{2}$ and liquid aluminum.

\section{Acknowledgements}

The authors thank Dr F.D. Meyer for supplying us with the $\mathrm{Al}_{3} \mathrm{BC}$ specimen and Prof. $\mathrm{H}$. Hillebrecht for fruitful discussions. High-pressure experiments at HASYLAB-DESY were supported by the GFZ-Potsdam under the MAX80 program.

\section{References}

[1] J.C. Viala, J. Bouix, V. Gonzalez, C. Esnouf, J. Mater. Sci. 32 (1997) 45594573.

[2] D.C. Halverson, A.J. Pyzik, I.A. Aksay, Ceram. Eng. Sci. Proc. 16 (1985) 736-744.

[3] F.D. Meyer, H. Hillebrecht, J. Alloys Compd. 252 (1997) 98-102.

[4] V.L. Solozhenko, T. Peun, J. Phys. Chem. Solids 58 (1997) 1321-1323.

[5] D.L. Decker, J. Appl. Phys. 42 (1971) 3239-3244.

[6] I.C. Getting, C. Kennedy, J. Appl. Phys. 41 (1970) 4552-4562.

[7] V.L. Solozhenko, F.D. Meyer, H. Hillebrecht, J. Solid State Chem. 154 (2000) 254-256.

[8] H. Hillebrecht, F.D. Meyer, Angew. Chem. Int. Ed. Engl. 35 (1996) 2499 2500. 